\title{
The economic impact of enoxaparin versus unfractionated heparin for prevention of venous thromboembolism in acute ischemic stroke patients
}

\author{
This article was published in the following Dove Press journal: \\ ClinicoEconomics and Outcomes Research \\ 20 April 2012 \\ Number of times this article has been viewed
}

\author{
Graham F Pineo' \\ Jay $\operatorname{Lin}^{2}$ \\ Lieven Annemans ${ }^{3}$ \\ 'Department of Medicine, University \\ of Calgary, Calgary, Alberta, Canada; \\ ${ }^{2}$ Novosys Health, Flemington, $\mathrm{NJ}$, \\ USA; ${ }^{3}$ Department of Medicine, \\ Ghent University, Ghent and Brussels \\ University, Brussels, Belgium
}

\begin{abstract}
Venous thromboembolism (VTE) is a common complication after acute ischemic stroke that can be prevented by the use of anticoagulants. Current guidelines from the American College of Chest Physicians recommend that patients with acute ischemic stroke and restricted mobility receive prophylactic low-dose unfractionated heparin or a low-molecular-weight heparin. Results from clinical studies, most recently from PREVAIL (PREvention of Venous Thromboembolism After Acute Ischemic Stroke with LMWH and unfractionated heparin), suggest that the low-molecular-weight heparin, enoxaparin, is preferable to unfractionated heparin for VTE prophylaxis in patients with acute ischemic stroke and restricted mobility. This is due to a better clinical benefit-to-risk ratio, with the added convenience of once-daily administration. In line with findings from modeling studies and real-world data in acutely ill medical patients, recent economic data indicate that the higher drug cost of enoxaparin is offset by the reduction in clinical events as compared with the use of unfractionated heparin for the prevention of VTE after acute ischemic stroke, particularly in patients with severe stroke. With national performance measures highlighting the need for hospitals to examine their VTE practices, the relative costs of different regimens are of particular importance to health care decision-makers. The data reviewed here suggest that preferential use of enoxaparin over unfractionated heparin for the prevention of VTE after acute ischemic stroke may lead to reduced VTE rates and concomitant cost savings in clinical practice.
\end{abstract}

Keywords: acute ischemic stroke, cost savings, enoxaparin, unfractionated heparin, venous thromboembolism

\section{Introduction}

Worldwide, stroke is the second leading cause of death ${ }^{1}$ and its impact is expected to increase with the westernization of lifestyles in developing countries. In addition to high rates of mortality, stroke is responsible for significant long-term morbidity, with permanent disability experienced by $15 \%-30 \%$ of stroke patients and $20 \%$ of patients requiring institutional care at 3 months after onset. ${ }^{2}$ There is also a considerable health care burden associated with long-term morbidity due to stroke, such that the total (direct and indirect) costs of stroke were estimated to be $\$ 73.9$ billion in 2010 in the United States alone. ${ }^{2}$

Approximately $85 \%$ of all strokes are ischemic events ${ }^{2,3}$ that usually occur as a result of thrombosis or embolism. Venous thromboembolism (VTE) is also a common, yet highly preventable, complication following stroke. ${ }^{4}$ To reduce the 
incidence of VTE in patients with acute ischemic stroke and restricted mobility, guidelines from the American College of Chest Physicians recommend prophylaxis with low-dose unfractionated heparin or a low-molecular-weight heparin (LMWH). ${ }^{5}$ Although none of the LMWHs is indicated for thromboprophylaxis specifically in patients with acute ischemic stroke, these patients are often categorized as medical patients with reduced mobility, a group of patients for which the LMWHs dalteparin and enoxaparin are indicated for thromboprophylaxis.

This review discusses the risk of VTE in stroke patients, describes studies evaluating the efficacy and safety of VTE prophylaxis after acute ischemic stroke, and details the relative costs of different thromboprophylaxis regimens, with particular emphasis on data from the PREVAIL (PREvention of Venous Thromboembolism After Acute Ischemic Stroke with LMWH and UFH) study. ${ }^{6-8}$

\section{Thromboembolic risk in stroke patients}

Following a first stroke, patients are at significantly increased risk of a further thrombotic event, ie, VTE (deep vein thrombosis or pulmonary embolism), recurrent stroke, or myocardial infarction. A recent study of 1,150,336 adult hospitalizations with ischemic stroke in the United States using data from the Nationwide Inpatient Sample of the Healthcare Cost and Utilization Project, demonstrated that although inhospital mortality decreased from 1998-1999 to 2006-2007, the largest increase in medical complications in these patients was observed for deep vein thrombosis $(0.46 \%$ versus $0.79 \%)$ and pulmonary embolism $(0.11 \%$ versus $0.27 \%) .{ }^{9}$ In the absence of thromboprophylaxis, $20 \%-75 \%$ of stroke patients may develop deep vein thrombosis, with the wide range depending on the methods used to detect deep vein thrombosis and the degree of lower limb paralysis. ${ }^{10,11}$ Pulmonary embolism is fatal in up to half of all cases. ${ }^{12}$ Indeed, pulmonary embolism is the third most common cause of death in stroke patients, after stroke itself and secondary infections, occurring in $1 \%-2 \%$ of patients. ${ }^{12}$ The risk of VTE is highest in the 14 days after stroke; however, deep vein thrombosis was present in $14 \%-33 \%$ of stroke patients in rehabilitation over 2 weeks after the primary event. ${ }^{12}$

Stroke patients are at increased risk of VTE as a result of their initial stroke and its consequences, such as limb paralysis. In line with other acutely ill medical patients, stroke patients often have multiple other complications, such as advanced age, immobility, obesity, and venous insufficiency. Comorbidities that further increase VTE risk are also common, including cancer, heart failure, and severe respiratory disease. ${ }^{13}$ For example, in the total patient population of a trial of thromboprophylaxis for the prevention of deep vein thrombosis in acute ischemic stroke, $52 \%$ of patients were aged over 70 years, $18 \%$ were obese, and $9 \%$ had varicose veins. ${ }^{14}$

\section{Preventing VTE after acute ischemic stroke: the role of antithrombotic agents}

Given the high risk and considerable consequences, prevention of VTE is crucially important following a stroke. However, it is essential to rule out hemorrhagic stroke and identify patients at increased risk of bleeding complications before prescribing pharmacological prophylaxis. Current guidelines from the American College of Chest Physicians recommend that patients with acute ischemic stroke and restricted mobility receive prophylactic low-dose subcutaneous unfractionated heparin or LMWH (Grade 1A). ${ }^{5}$ For patients who have contraindications to anticoagulants, intermittent pneumatic compression devices or elastic stockings are recommended (Grade 1B). Guidelines from the American Heart Association/American Stroke Association also recommend subcutaneous administration of anticoagulants in immobilized patients with acute ischemic stroke to prevent deep vein thrombosis (Class I, level of evidence A). ${ }^{15}$ These guidelines consider aspirin a potential intervention to prevent deep vein thrombosis, but note that it is less effective than anticoagulants (Class IIA, level of evidence A). ${ }^{15}$ Recent guidelines from the American College of Physicians recommend pharmacologic prophylaxis with unfractionated heparin or a LMWH, or a related drug for VTE in medical patients (including stroke patients) unless the assessed risk for bleeding outweighs the likely benefits. ${ }^{16}$

\section{Unfractionated heparin}

Thromboprophylaxis with unfractionated heparin has been shown to reduce the incidence of VTE after acute ischemic stroke compared with placebo. ${ }^{10,17,18}$ Sandercock et al ${ }^{17}$ reviewed four small trials in stroke patients and reported an overall reduction of $84 \%$ in VTE events with unfractionated heparin prophylaxis versus placebo or no treatment. However, data were inadequate to enable conclusions to be drawn on the safety of unfractionated heparin prophylaxis, particularly with respect to hemorrhagic transformation and bleeding in patients with known intracerebral hemorrhage. ${ }^{17}$ Systematic screening for hemorrhagic transformation in patients with cerebral infarcts would be able to provide firm 
evidence of this complication, but none of the trials analyzed has this as a prespecified analysis. Also, the included studies were too small to provide firm conclusions regarding safety. ${ }^{17}$ Subsequently, the International Stroke Trial, a large randomized study (approximately 20,000 patients), investigated the efficacy and safety of unfractionated heparin administered at either $5000 \mathrm{IU}$ or $12,500 \mathrm{IU}$ twice daily. ${ }^{18}$ Taken together, unfractionated heparin significantly reduced the incidence of pulmonary embolism compared with control $(0.5 \%$ versus $0.8 \% ; P<0.05)$, but was associated with a significant increase in hemorrhagic stroke $(1.2 \%$ versus $0.4 \%$; $P<0.001)$ and bleeding complications $(1.3 \%$ versus $0.4 \%$; $P<0.001)^{18}$

\section{Low-molecular-weight heparins}

Outcomes following prophylaxis with LMWHs or danaparoid, a heparinoid, were investigated in a meta-analysis of 10 small controlled trials $(\mathrm{n}=2855) .{ }^{19}$ LMWHs/danaparoid versus control was associated with significant reductions in prospectively identified deep vein thrombosis (odds ratio [OR] 0.27 ; $95 \%$ confidence interval $[\mathrm{CI}] 0.08-0.96)$ and symptomatic pulmonary embolism (OR 0.34; 95\% CI 0.17-0.69). However, significant increases in major extracranial hemorrhage were observed with LMWHs (OR 2.17; 95\% CI 1.10-4.28).

Subsequently, a number of head-to-head studies have compared LMWHs with unfractionated heparin for the prevention of VTE after stroke. ${ }^{6,14,19,20}$ In one study, unfractionated heparin 5000 IU three times daily and the LMWH enoxaparin administered at $40 \mathrm{mg}$ once daily were investigated in 212 patients. ${ }^{14}$ The main outcome measures of symptomatic or asymptomatic deep vein thrombosis detected by venography, pulmonary embolism, death from any cause, intracranial hemorrhage including hemorrhagic infarction, or any other major bleeding occurred in $37.7 \%$ of patients in the enoxaparin group and $49.1 \%$ in the unfractionated heparin group $(P=0.127)$. Bleeding complications were experienced by $2.8 \%$ of patients in the enoxaparin group and $1.9 \%$ in the unfractionated heparin group. Of note, numerically fewer patients treated with enoxaparin (13.2\%) compared with unfractionated heparin (18.9\%) had evidence of hemorrhagic transformation of acute ischemic stroke.

The PROTECT study (Prophylaxis of Thromboembolic Events by Certoparin Trial) compared the LMWH certoparin (3000 U anti-Xa once daily; $\mathrm{n}=272$ ) with unfractionated heparin (5000 IU three times daily; $n=273$ ) in the prevention of VTE following stroke. ${ }^{21}$ The composite primary endpoint of proximal symptomatic or asymptomatic deep vein thrombosis detected by ultrasonography, pulmonary embolism, or death related to VTE during treatment occurred in $7.0 \%$ of patients in the certoparin group compared with $9.7 \%$ in the unfractionated heparin group, demonstrating that certoparin was as effective as unfractionated heparin ( $P=0.0011$ for noninferiority). Major bleeding occurred in $1.1 \%$ of patients allocated to certoparin and $1.8 \%$ of patients allocated to unfractionated heparin.

In the PREVAIL (PREvention of Venous Thromboembolism After Acute Ischemic Stroke with LMWH and unfractionated heparin) study of 1762 patients with acute ischemic stroke and restricted mobility, enoxaparin at a dose of $40 \mathrm{mg}$ once daily reduced the risk of the composite primary endpoint of symptomatic or asymptomatic deep vein thrombosis, detected by contrast venography, or symptomatic or fatal pulmonary embolism by $43 \%$ compared with unfractionated heparin 5000 IU twice daily (10\% versus $18 \%$, respectively; relative risk $0.57 ; 95 \% \mathrm{CI} 0.44-0.76 ; P=0.0001) .{ }^{6}$ Bleeding complications were similar between groups (both $8 \%$ ). The composite of symptomatic intracranial and major extracranial hemorrhage was not significantly different between enoxaparin and unfractionated heparin (11/877 [1.2\%] versus (6/872) $[0.7 \%] ; P=0.23)$, but there was a slight, clinically significant, excess in major extracranial hemorrhage alone with enoxaparin compared with unfractionated heparin (7/877 [0.8\%] versus 0/872 [0.0\%]; $P=0.015)$.

In the PREVAIL study, the rate of VTE was higher in patients with more severe strokes (National Institutes of Health Stroke Scale [NIHSS] scores $\geq 14$ ) than less severe strokes (NIHSS scores $<14$ ). Prophylaxis with enoxaparin was associated with a reduced risk of VTE compared with unfractionated heparin in both stroke severity groups (Figure 1). ${ }^{6}$

Further, a post hoc analysis of data from the PREVAIL study indicate that enoxaparin prophylaxis confers a reduced risk of VTE, as compared with unfractionated heparin, in multiple patient subgroups. This includes several subgroups with or without risk factors in addition to stroke, such as patients with diabetes, obesity, and advanced age (Figure 1). ${ }^{6,22}$ More recently, a subanalysis of PREVAIL has been conducted to study the long-term neurological outcomes associated with the use of enoxaparin compared with unfractionated heparin. ${ }^{23}$ Similar improvements in NIHSS and modified Rankin scale scores were observed in both groups over the 90-day follow-up period. The incidence of intracranial hemorrhage was similar in the enoxaparin group and the unfractionated heparin group (2.3\% versus $2.5 \%$, respectively).

Data from PREVAIL, PROTECT, and seven other randomized studies were analyzed in a Cochrane review 


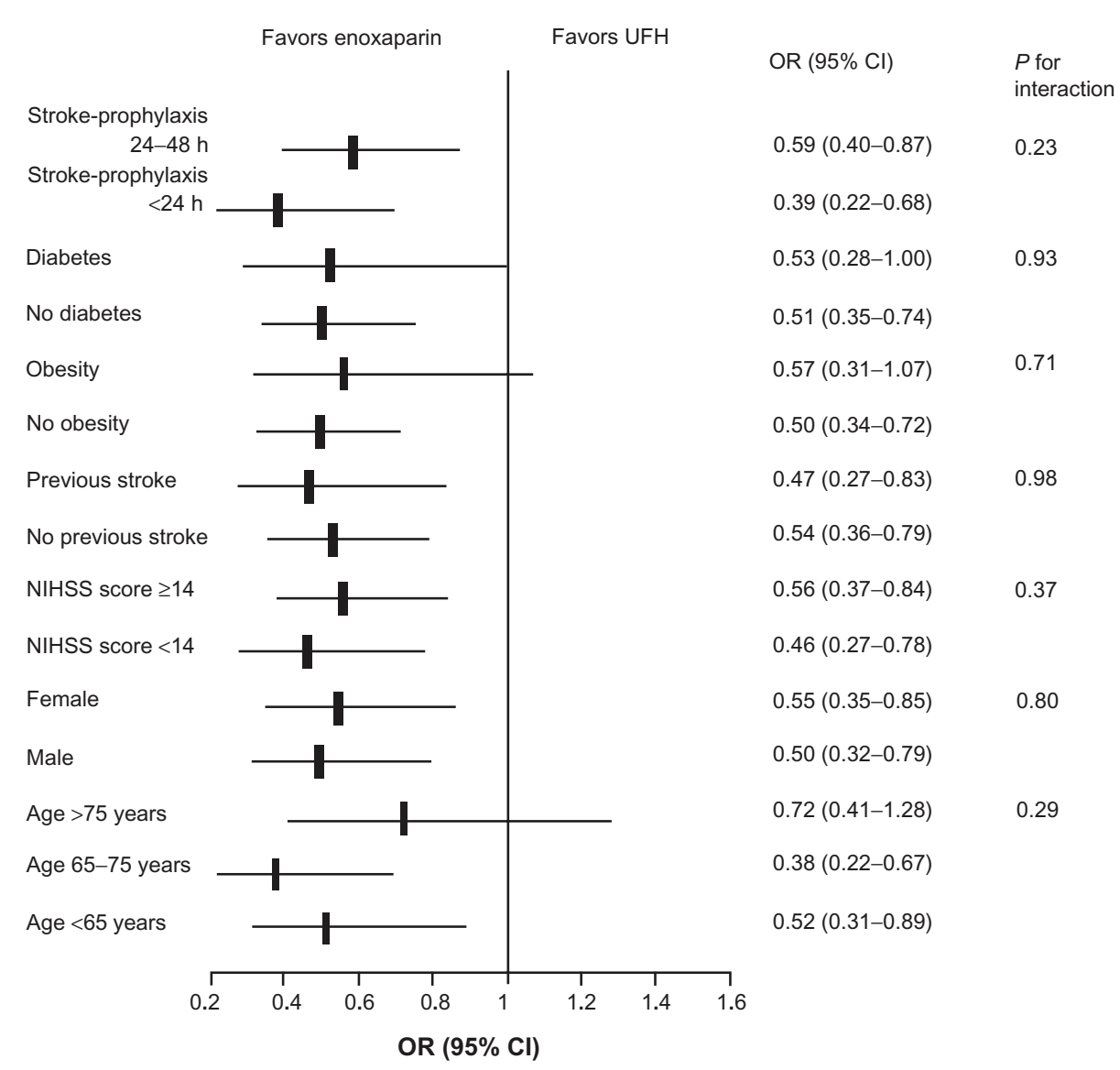

Figure I Relative risk of venous thromboembolism for enoxaparin compared with UFH in patients with acute ischemic stroke by patient characteristics in the PREVAIL (PREvention of Venous Thromboembolism After Acute Ischemic Stroke with LMWH [low-molecular-weight heparin] and UFH) study. ${ }^{6}$

Reproduced from Sherman DG, et al. Lancet. 2007;369:1347-55 (c) 2007, with permission from Elsevier.

Abbreviations: $\mathrm{Cl}$, confidence interval; NIHSS, National Institutes of Health Stroke Scale; OR, odds ratio; UFH, unfractionated heparin.

of LMWHs/heparinoid versus unfractionated heparin in 3137 patients with acute ischemic stroke. ${ }^{20}$ Allocation to the LMWH group was associated with a reduction in deep vein thrombosis compared with unfractionated heparin (OR 0.55; 95\% CI 0.44-0.70); however, the authors concluded that there were too few data to provide reliable information regarding their effects on other important outcomes, including death and intracranial hemorrhage.

\section{Other anticoagulant agents}

Several other anticoagulant agents have been studied in medical patients or are currently being assessed in randomized controlled trials. These include fondaparinux, rivaroxaban, and apixaban. Fondaparinux (2.5 mg once daily, for 6-14 days) reduced VTE in older acute medical patients compared with placebo, with a relative risk reduction of $46.7 \%$ (95\% CI 7.7-69.3). No concomitant increase in major bleeding events, which occurred in $0.2 \%$ of patients in both groups, was associated with fondaparinux. ${ }^{24}$ MAGELLAN (Multicenter, Randomized, Parallel Group Efficacy and Safety
Study for the Prevention of Venous Thromboembolism in Hospitalized Medically Ill Patients Comparing Rivaroxaban With Enoxaparin) has recently been completed, and ADOPT (A Phase III Randomized, Double-Blind, Parallel-group, Multi-center Study of the Safety and Efficacy of Apixaban for Prophylaxis of Venous Thromboembolism in Acutely Ill Medical Subjects During and Following Hospitalization) is currently underway. These trials are designed to assess the use of extended duration prophylaxis with apixaban and rivaroxaban, for 30 and 35 days, respectively, in comparison with enoxaparin during hospitalization (6-14 days) and placebo after hospital discharge. Preliminary results from MAGELLAN showed that rivaroxaban $10 \mathrm{mg}$ once daily was noninferior to enoxaparin $40 \mathrm{mg}$ once daily for the primary endpoint of major VTE (asymptomatic and symptomatic proximal deep vein thrombosis, nonfatal pulmonary embolism, and VTE-related death) at day $10 \pm 4$ (2.7\% versus $2.7 \%$; $P$ for noninferiority $=0.0025$ ). For the extended period of rivaroxaban (35 \pm 4 days) versus placebo, rivaroxaban was superior $(4.4 \%$ versus $5.7 \% ; P=0.02$ ). Clinically relevant bleeding rates 
were low but significantly higher with rivaroxaban across the entire study $(2.8 \%$ versus $1.2 \% ; P<0.0001$ for days $1-10$ and $1.4 \%$ versus $0.5 \% ; P<0.0001$ for days $11-35)$. Subgroup analysis confirmed the overall efficacy and bleeding results for most clinical groups including patients with acute ischemic stroke, although the number of patients with acute ischemic stroke was small. ${ }^{25}$ Furthermore, rivaroxaban, apixaban, and the thrombin inhibitor, dabigatran, have been assessed for the prevention of stroke and systemic embolism in patients with atrial fibrillation. ${ }^{26-28}$ However, no studies are currently underway directly assessing the efficacy of these agents in reducing VTE following acute ischemic stroke.

\section{Mechanical prophylaxis}

Intermittent pneumatic compression devices or graduated compression stockings are recommended as thromboprophylaxis for patients who have contraindications to anticoagulants. The relationship between symptomatic VTE and the use of stockings was assessed based on observational data from TAIST (the Tinzaparin in Acute Ischemic Stroke Trial) which compared the LMWH, tinzaparin, (175 IU/kg or $100 \mathrm{IU} / \mathrm{kg}$ ) with aspirin $300 \mathrm{mg} .{ }^{29}$ Patients wearing bilateral graduated compression stockings for 10 days $(n=374)$ had a nonsignificant one-third reduction in the odds of VTE as compared with those who wore no stockings or wore them for less than 10 days (OR 0.65; 95\% CI 0.26-1.65).

The large CLOTS (Clots in Legs Or sTockings after Stroke) trials were designed to investigate further the role of mechanical prophylaxis for preventing VTE in patients with acute stroke. In CLOTS trial 1 of 2518 immobile patients with acute ischemic stroke, symptomatic or asymptomatic proximal deep vein thrombosis, detected by ultrasonography, occurred in $10.0 \%$ of patients allocated to thigh-length graduated compression stockings and in $10.5 \%$ allocated to avoid graduated compression stockings, resulting in a nonsignificant absolute risk reduction of $0.5 \%$ (95\% CI -1.9-2.9).${ }^{30}$ Skin breaks, ulcers, blisters, and skin necrosis were more common in patients allocated graduated compression stockings than in the control group (5\% versus $1 \%$, respectively; OR 4.18; $95 \%$ CI 2.40-7.27). In CLOTS trial 2 ( $\mathrm{n}=3114)$, symptomatic or asymptomatic proximal deep vein thrombosis, detected by ultrasonography, occurred in $6.3 \%$ of patients who received thigh-length stockings and $8.8 \%$ who received below-knee stockings, an odds reduction of 31\% (95\% CI 9-47; $P=0.008$ for the absolute difference). ${ }^{31}$ Skin breaks occurred in $3.9 \%$ of patients who received thigh-length stockings and $2.9 \%$ of patients who received below-knee stockings (OR 1.38; 95\% CI $0.93-2.04 ; P=0.11)$. These results are intriguing because it seems that thigh-length stockings were ineffective in trial 1, but more effective than below-knee stockings in trial 2. Further information on the use of mechanical prophylaxis will be obtained from the ongoing CLOTS trial 3, which is investigating the use of intermittent pneumatic compression versus avoidance of intermittent pneumatic compression.

\section{Cost comparisons}

Recently, there has been an increased focus on the total cost of different medical regimens within hospitals in the United States. Such studies take drug-acquisition costs into consideration and also costs for clinical events (Table 1). ${ }^{7,8,32-34}$ Two studies using a cost-effectiveness analysis model based on hypothetical cohorts of medically ill patients have investigated the cost-effectiveness of enoxaparin and unfractionated heparin. ${ }^{32,33}$ In a simulated cohort of 10,000 patients using a decision-analytic model with parameter estimates derived from published clinical trials, expected numbers of deaths attributable to VTE or drug complications were 37 with enoxaparin $40 \mathrm{mg}$ once daily, 53 with unfractionated heparin 5000 IU twice daily, and 81 with no prophylaxis. ${ }^{32}$ In 2001, corresponding expected costs of prevention, diagnosis, and management of VTE were $\$ 3,502,000$ for enoxaparin, $\$ 3,772,000$ for unfractionated heparin, and $\$ 3,105,000$ for no prophylaxis. The incremental cost per death averted with enoxaparin prophylaxis versus no prophylaxis was $\$ 9100$. Enoxaparin was a dominant strategy over unfractionated heparin by being both more effective and less costly.

In a more recent study by Deitelzweig et al, ${ }^{33}$ a decisionanalytic model, with model parameters derived from published clinical trials and other secondary sources, compared the long-term clinical effectiveness, safety, and direct medical costs between hypothetical cohorts of 10,000 medical patients receiving enoxaparin $40 \mathrm{mg}$ once daily, unfractionated heparin 5000 IU twice daily, or no prophylaxis. The estimated incidence of VTE at 2 years (including recurrent VTE) was $6.8 \%$ with enoxaparin, $7.9 \%$ with unfractionated heparin, and $17.9 \%$ with no prophylaxis. Two-year mortality occurred in $15.7 \%$ of enoxaparin patients and $16.0 \%$ of unfractionated heparin patients. The incidence of major bleeding was $0.7 \%, 1.2 \%$, and $0.6 \%$ for enoxaparin, unfractionated heparin, and no prophylaxis, respectively. Total average costs per patient were $\$ 1264$ for enoxaparin, $\$ 1585$ for unfractionated heparin, and $\$ 2245$ for no prophylaxis; therefore, enoxaparin was dominant over the two alternative strategies. No realistic parameter changes resulted in prophylaxis using enoxaparin being more costly than unfractionated heparin prophylaxis. 
Table I Cost comparison studies for use of unfractionated heparin versus enoxaparin for thromboprophylaxis

\begin{tabular}{|c|c|c|c|c|c|c|c|}
\hline \multirow[t]{2}{*}{ Reference } & \multirow{2}{*}{$\begin{array}{l}\text { Patient } \\
\text { population }\end{array}$} & \multirow[t]{2}{*}{ Parameter estimates } & \multirow[t]{2}{*}{ Cost estimate } & \multicolumn{2}{|c|}{ Drug acquisition cost, $\$$} & \multicolumn{2}{|c|}{ Total cost, $\$$} \\
\hline & & & & UFH & Enoxaparin & UFH & Enoxaparin \\
\hline $\begin{array}{l}\text { McGarry } \\
\text { et } \mathrm{al}^{32}\end{array}$ & Medical patients & $\begin{array}{l}\text { Decision-analytic model } \\
\text { based on a hypothetical } \\
\text { cohort }(\mathrm{n}=10,000) \text {; } \\
\text { model parameters based } \\
\text { on clinical trials and other } \\
\text { secondary sources }\end{array}$ & $\begin{array}{l}\text { Cost per patient } \\
\text { ( } 30 \text { days) }\end{array}$ & 112 & 172 & 3772 & 3502 \\
\hline $\begin{array}{l}\text { Deitelzweig } \\
\text { et } \mathrm{al}^{33}\end{array}$ & Medical patients & $\begin{array}{l}\text { Decision-analytic model } \\
\text { based on a hypothetical } \\
\text { cohort }(n=10,000) \text {; } \\
\text { model parameters based } \\
\text { on clinical trials and other } \\
\text { secondary sources }\end{array}$ & $\begin{array}{l}\text { Cost per patient } \\
(2 \text { years) }\end{array}$ & 68 & 211 & 1585 & 1264 \\
\hline $\begin{array}{l}\text { Burleigh } \\
\text { et } \mathrm{al}^{34}\end{array}$ & $\begin{array}{l}\text { Acute ischemic } \\
\text { stroke } \\
\text { subpopulation }\end{array}$ & $\begin{array}{l}\text { Real-world data from } \\
\text { a large inpatient database } \\
\text { ( } \mathrm{n}=153,552 \text { ischemic } \\
\text { stroke patients) }\end{array}$ & $\begin{array}{l}\text { Hospital cost } \\
\text { per patient }\end{array}$ & 617 & 803 & 8911 & 8608 \\
\hline Pineo et $\mathrm{al}^{7}$ & $\begin{array}{l}\text { Acute ischemic } \\
\text { stroke }\end{array}$ & $\begin{array}{l}\text { Decision-analytic model } \\
\text { based on PREVAIL } \\
\text { clinical trial }\end{array}$ & $\begin{array}{l}\text { Payer cost per } \\
\text { patient }\end{array}$ & 59 & 260 & 2913 & 2018 \\
\hline Pineo et $\mathrm{al}^{8}$ & $\begin{array}{l}\text { Acute ischemic } \\
\text { stroke }\end{array}$ & $\begin{array}{l}\text { Decision-analytic model } \\
\text { based on PREVAIL } \\
\text { clinical trial }\end{array}$ & $\begin{array}{l}\text { Hospital cost } \\
\text { per patient }\end{array}$ & 259 & 360 & 922 & 782 \\
\hline
\end{tabular}

Abbreviations: PREVAIL, PREvention of Venous Thromboembolism After Acute Ischemic Stroke with LMWH [low-molecular-weight heparin] and UFH; UFH, unfractionated heparin.

In a 2006 study, costs were investigated in different medical patient groups at risk of VTE who received a LMWH or unfractionated heparin based on real-world data from a large inpatient database. ${ }^{34}$ In the 153,552 patients with acute ischemic stroke, the mean \pm standard deviation total drug cost per patient was $\$ 803 \pm 993$ in the LMWH group and $\$ 617 \pm 2701$ in the unfractionated heparin group. Importantly, the mean total hospital cost per patient was $\$ 8608 \pm 7190$ for enoxaparin and $\$ 8911 \pm 8291$ for unfractionated heparin.

Recently, data from PREVAIL were used to investigate the economic impact further, from the payer perspective and the hospital perspective, of a LMWH versus unfractionated heparin specifically in patients after acute ischemic stroke. ${ }^{7,8}$ For the payer perspective, payer costs for clinical events were based on the median cost in Centers for Medicare and Medicaid Services claim information. The average costs of clinical events per patient to the payer were $\$ 1758$ with enoxaparin and \$2854 for unfractionated heparin, resulting in a net saving of $\$ 1096$ with enoxaparin. ${ }^{7}$ The drug costs were higher for enoxaparin than unfractionated heparin ( $\$ 260$ versus $\$ 59$, respectively); however, when the total cost of clinical events and drug costs were considered together, enoxaparin was associated with a total cost saving of $\$ 895$ per patient compared with unfractionated heparin $(\$ 2018$ with enoxaparin versus $\$ 2913$ with unfractionated heparin).
In addition to this model scenario that used the VTE definition from the PREVAIL study, which includes symptomatic or asymptomatic deep vein thrombosis, symptomatic pulmonary embolism, or fatal pulmonary embolism, ${ }^{6}$ two other model scenarios were used to calculate costs in order to account for different definitions of VTE. The second model scenario grouped events into two categories, major VTE including pulmonary embolism, symptomatic deep vein thrombosis and asymptomatic proximal deep vein thrombosis, and minor VTE defined as asymptomatic distal deep vein thrombosis only. The third model scenario used the European Committee for Medicinal Products for Human Use (CHMP) definition, which includes well documented proximal deep vein thrombosis, well documented nonfatal pulmonary embolism, and death from all causes including pulmonary embolism. Only the definition of efficacy endpoints changed between the three scenarios and the definition of bleeding was consistent across all models, and included intracranial hemorrhage, major extracranial hemorrhage, and minor hemorrhage for all three model scenarios. ${ }^{7}$ Despite higher drug costs for enoxaparin compared with unfractionated heparin, total cost per patient remained lower for enoxaparin in all three scenarios. Savings ranged from $\$ 517$ per patient in the CHMP scenario to $\$ 895$ per patient in the PREVAIL scenario. In patients with more severe strokes (NIHSS scores $\geq 14$ ), the use of enoxaparin 
over unfractionated heparin resulted in even greater total cost-savings ( $\$ 1800$ per patient) than in patients with less severe stroke (NIHSS scores $<14$; $\$ 488$ per patient).

In a similar analysis, costs for hospitals were evaluated rather than costs to the payer. The costs of clinical events for hospitals were based on mean hospital costs in the Premier Perspective ${ }^{\mathrm{TM}}$ multihospital database, which is one of the largest United States hospital clinical and economic databases. This database contains detailed United States inpatient care records from over 600 hospitals of principal and secondary diagnoses, inpatient procedures, administered laboratory tests, dispensed drugs, and demographic information. The average cost to the hospital, when taking into account the costs of VTE and bleeding, was similarly lower with enoxaparin than with unfractionated heparin (\$422 versus \$662, respectively), with a net saving of \$240 per patient if enoxaparin was used. ${ }^{8}$ The drug costs, including drug administration costs, were higher for enoxaparin than unfractionated heparin (\$360 versus $\$ 259$, respectively); however, when the total cost of clinical events and drug costs were considered together, enoxaparin was associated with a total cost saving of $\$ 140$ per patient compared with unfractionated heparin (\$782 with enoxaparin versus $\$ 922$ with unfractionated heparin). Again, the total hospital cost savings were greater when enoxaparin was used instead of unfractionated heparin in patients with more severe stroke (cost-saving $\$ 287$ if NIHSS score $\geq 14$ versus $\$ 71$ if NIHSS score $<14$ ). Sensitivity analyses were performed where cost parameters were varied by $\pm 5 \%, \pm 10 \%, \pm 15 \%, \pm 30 \%$, and $\pm 40 \%$; enoxaparin remained less costly than unfractionated heparin in all cases. In a multivariate analysis, differences in enoxaparin drug costs, hospital costs for deep vein thrombosis, and probability of deep vein thrombosis for patients on enoxaparin were the factors with the greatest effect on the overall cost. The only scenario where the higher drug cost of prophylaxis with enoxaparin was not completely offset by the reduction in events compared with unfractionated heparin, was a scenario which used a published ratio of asymptomatic deep vein thrombosis to symptomatic VTE to account for the fact that not all VTE events in the real-world present with symptoms prompting treatment and, therefore, costs. This scenario was limited by the fact that the ratio was derived from different patient populations receiving different anticoagulants than stroke patients. ${ }^{8}$

The Joint Commission and the National Quality Forum in the United States have recently introduced a set of quality assurance measures within the "National Consensus Standards for the Prevention and Care of Venous Thromboembolism" project, ${ }^{35}$ with the specific goal of improving inhospital VTE assessment, diagnosis, prophylaxis, and treatment. Three process measures focus on VTE prevention, ie, VTE-1 assesses the proportion of patients who received any prophylaxis, VTE-2 evaluates prophylaxis after admission to the intensive care unit, and VTE- 6 assesses the incidence of potentially preventable hospital-acquired VTE. With national performance measures highlighting the need for hospitals to examine their VTE practices, the relative costs of different regimens are of particular importance to health care decision-makers. The use of clinically effective and cost-effective prophylaxis regimens should help to prevent VTE and its clinical and economic consequences, and ensure hospitals meet performance measures. In addition, the CMS has recognized hospital-acquired VTE as a preventable condition. ${ }^{36}$ CMS have classified VTE after total knee or hip replacement as a preventable hospital-acquired condition and will not pay any incremental costs, leaving hospitals to bear the financial burden. Whether this or other financial-based incentives will be extended to include VTE after acute ischemic stroke remains to be seen.

\section{Conclusion}

VTE is a common complication after acute ischemic stroke. ${ }^{4}$ Although none of the LMWHs is indicated for thromboprophylaxis specifically in patients with acute ischemic stroke, guidelines from the American College of Chest Physicians recommend that patients with acute ischemic stroke and restricted mobility receive prophylactic low-dose subcutaneous unfractionated heparin or a LMWH, unless contraindicated. ${ }^{5}$ Results from clinical studies suggest that enoxaparin is preferable to unfractionated heparin for VTE prophylaxis in patients with acute ischemic stroke and restricted mobility due to a better clinical benefit-to-risk ratio, with the added convenience of once-daily administration. ${ }^{6}$ In line with findings from modeling studies and real-world data in acutely ill medical patients, recent economic data indicate that the higher drug cost of enoxaparin is offset by the reduction in clinical events as compared with the use of unfractionated heparin for the prevention of VTE, particularly in patients with severe stroke. ${ }^{7}$ However, this cost-analysis in stroke patients is based on one open-label, randomized, controlled trial only. The data reviewed here suggest that preferential use of enoxaparin over unfractionated heparin may lead to reduced VTE rates and concomitant cost-savings in clinical practice. Furthermore, a once-daily injection has the advantage in clinical practice of simplifying treatment and improving compliance with both patients and physicians, 
decreasing nursing time, and providing prophylaxis in an outpatient setting in addition to decreasing costs. ${ }^{37}$

\section{Disclosure}

The authors received editorial and writing support in the preparation of this manuscript from Hester van Lier, PhD, of Excerpta Medica, funded by sanofi-aventis US Inc. Graham Pineo was a member of the Steering Committee for the PREVAIL study and has received honoraria and consulting fees from sanofi-aventis, Boehringer-Ingelheim, Bayer, and BMS/Pfizer.

\section{References}

1. Murray CJ, Lopez AD. Mortality by cause of death for eight regions of the world. Global Burden of Disease Study. Lancet. 1997;349 (9061):1269-1276.

2. Writing Group Member Lloyd-Jones D, Adams RJ, Brown TM, et al. Heart disease and stroke statistics - 2010 update: a report from the American Heart Association. Circulation. 2010;121(7):e46-e215.

3. Broderick J, Brott T, Kothari R, et al. The Greater Cincinnati/Northern Kentucky Stroke Study: preliminary first-ever and total incidence rates of stroke among blacks. Stroke. 1998;29(2):415-421.

4. Kelly J, Rudd A, Lewis R, Hunt BJ. Venous thromboembolism after acute stroke. Stroke. 2001;32(1):262-267.

5. Albers GW, Amarenco P, Easton JD, Sacco RL, Teal P; American College of Chest Physicians. Antithrombotic and thrombolytic therapy for ischemic stroke: American College of Chest Physicians Evidence-Based Clinical Practice Guidelines (8th Edition). Chest. 2008;133 (6 Suppl):630S-669S

6. Sherman DG, Albers GW, Bladin C, et al. The efficacy and safety of enoxaparin versus unfractionated heparin for the prevention of venous thromboembolism after acute ischaemic stroke (PREVAIL Study): an open-label randomised comparison. Lancet. 2007;369 (9570):1347-1355.

7. Pineo G, Lin J, Stern L, Subrahmanian T, Annemans L. Economic impact of enoxaparin after acute ischemic stroke based on PREVAIL. Clin Appl Thromb Hemost. 2011;17(2):150-157.

8. Pineo G, Lin J, Stern L, Subrahmanian T, Annemans L. Economic impact of enoxaparin versus unfractionated heparin for venous thromboembolism prophylaxis in patients with acute ischemic stroke: a hospital perspective of the PREVAIL trial. J Hosp Med. 2012;7(3):176-182.

9. Tong X, Kuklina EV, Gillespie C, George MG. Medical complications among hospitalizations for ischemic stroke in the United States from 1998 to 2007. Stroke. 2010;41(5):980-986.

10. McCarthy ST, Turner J. Low-dose subcutaneous heparin in the prevention of deep vein thrombosis and pulmonary emboli following acute stroke. Age Ageing. 1986;15(2):84-88.

11. Turpie AG. Prophylaxis of venous thromboembolism in stroke patients. Semin Thromb Hemost. 1997;23(2):155-157.

12. Harvey RL, Lovell LL, Belanger N, Roth EJ. The effectiveness of anticoagulant and antiplatelet agents in preventing venous thromboembolism during stroke rehabilitation: a historical cohort study. Arch Phys Med Rehabil. 2004;85(7):1070-1075.

13. Geerts WH, Bergqvist D, Pineo GF, et al. Prevention of venous thromboembolism: American College of Chest Physicians Evidence-Based Clinical Practice Guidelines (8th Edition). Chest. 2008;133(6 Suppl): $381 \mathrm{~S}-453 \mathrm{~S}$.

14. Hillbom M, Erilä T, Sotaniemi K, Tatlisumak T, Sarna S, Kaste M. Enoxaparin versus heparin for prevention of deep vein thrombosis in acute ischaemic stroke: a randomized, double-blind study. Acta Neurol Scand. 2002;106(2):84-92.
15. Adams HP Jr, del Zoppo G, Alberts MJ, et al. Guidelines for the early management of adults with ischemic stroke: a guideline from the American Heart Association/American Stroke Association Stroke Council, Clinical Cardiology Council, Cardiovascular Radiology and Intervention Council, and the Atherosclerotic Peripheral Vascular Disease and Quality of Care Outcomes in Research Interdisciplinary Working Groups: The American Academy of Neurology affirms the value of this guideline as an educational tool for neurologists. Circulation. 2007;115(20):e478-e534.

16. Qaseem A, Chou R, Humphrey LL, Starkey M, Shekelle P; for the Clinical Guidelines Committee of the American College of Physicians. Venous thromboembolism prophylaxis in hospitalized patients: a clinical practice guideline from the American College of Physicians. Ann Intern Med. 2011;155(9):625-632.

17. Sandercock PA, van den Belt AG, Lindley RI, Slattery J. Antithrombotic therapy in acute ischaemic stroke: an overview of the completed randomised trials. J Neurol Neurosurg Psychiatry. 1993;56(1): $17-25$.

18. International Stroke Trial Collaborative Group. The International Stroke Trial (IST): a randomised trial of aspirin, subcutaneous heparin, both, or neither among 19435 patients with acute ischaemic stroke. Lancet. 1997;349(9065):1569-1581.

19. Bath PM, Iddenden R, Bath FJ. Low-molecular-weight heparins and heparinoids in acute ischemic stroke: a meta-analysis of randomized controlled trials. Stroke. 2000;31(7):1770-1778.

20. Sandercock PA, Counsell C, Tseng MC. Low-molecular-weight heparins or heparinoids versus standard unfractionated heparin for acute ischaemic stroke. Cochrane Database Syst Rev. 2008;3:CD000119.

21. Diener HC, Ringelstein EB, von Kummer R, et al. Prophylaxis of thrombotic and embolic events in acute ischemic stroke with the lowmolecular-weight heparin certoparin: results of the PROTECT Trial. Stroke. 2006;37(1):139-144.

22. Petrauskiene V, Falk M, Waernbaum I, Norberg M, Eriksson JW. The risk of venous thromboembolism is markedly elevated in patients with diabetes. Diabetologia. 2005;48(5):1017-1021.

23. Kase CS, Albers GW, Bladin C, et al. Neurological outcomes in patients with ischemic stroke receiving enoxaparin or heparin for venous thromboembolism prophylaxis: subanalysis of the Prevention of VTE after Acute Ischemic Stroke with LMWH (PREVAIL) study. Stroke. 2009;40(11):3532-3540.

24. Cohen AT, Davidson BL, Gallus AS, et al. Efficacy and safety of fondaparinux for the prevention of venous thromboembolism in older acute medical patients: randomised placebo controlled trial. $B M J$. 2006;332(7537):325-329.

25. Cohen AT, Spiro TE, Buller HR, et al. Rivaroxaban versus enoxaparin for the prevention of venous thromboembolism in acutely ill medical patients: Magellan sub-group analyses. Abstract 0-MO-034. Proceedings of the 23rd Congress of the International Society on Thrombosis Haemostasis, July 23-28, 2011. Kyoto, Japan.

26. Mahaffey K. Stroke prevention using the oral direct factor Xa inhibitor rivaroxaban compared with warfarin in patients with nonvalvular atrial fibrillation (ROCKET AF). Proceedings of the American Heart Association 2010 Scientific Sessions, November 15, 2010. Chicago, IL.

27. Granger CB, Alexander JH, McMurray JJ, et al. Apixaban versus warfarin in patients with atrial fibrillation. $N$ Engl J Med. 2011; 365(11):981-992.

28. Wallentin L, Yusuf S, Ezekowitz MD, et al. Efficacy and safety of dabigatran compared with warfarin at different levels of international normalised ratio control for stroke prevention in atrial fibrillation: an analysis of the RE-LY trial. Lancet. 2010;376(9745): 975-983.

29. Sprigg N, Gray LJ, Bath PM, et al. Compression stockings and the prevention of symptomatic venous thromboembolism: data from the Tinzaparin in Acute Ischemic Stroke Trial. J Stroke Cerebrovasc Dis. 2005;14(5):203-209. 
30. CLOTS Trials Collaboration, Dennis M, Sandercock PA, et al. Effectiveness of thigh-length graduated compression stockings to reduce the risk of deep vein thrombosis after stroke (CLOTS trial 1): a multicentre, randomised controlled trial. Lancet. 2009;373(9679): 1958-1965.

31. CLOTS (Clots in Legs Or sTockings after Stroke) Trial Collaboration. Thigh-length versus below-knee stockings for deep venous thrombosis prophylaxis after stroke: a randomized trial. Ann Intern Med. 2010;153(9):553-562.

32. McGarry LJ, Thompson D, Weinstein MC, Goldhaber SZ. Cost effectiveness of thromboprophylaxis with a low-molecular-weight heparin versus unfractionated heparin in acutely ill medical inpatients. Am J Manag Care. 2004;10(9):632-642.

33. Deitelzweig SB, Becker R, Lin J, Benner J. Comparison of the two-year outcomes and costs of prophylaxis in medical patients at risk of venous thromboembolism. Thromb Haemost. 2008;100(5):810-820.
34. Burleigh E, Wang C, Foster D, et al. Thromboprophylaxis in medically ill patients at risk for venous thromboembolism. Am J Health Syst Pharm. 2006;63(20 Suppl 6):S23-S29.

35. The Joint Commission. Venous thromboembolism core measure set. Available from: http://www.jointcommission.org/Performance Measurement/PerformanceMeasurement/VTE.htm. Accessed November 18, 2011.

36. US Department of Health and Human Services. Centers for Medicare and Medicaid Services. Hospital-acquired conditions. Available from: http://www.cms.gov/HospitalAcqCond/06_Hospital-Acquired Conditions.asp\#TopOfPage. Accessed November 18, 2011.

37. Pineo GF, Hull RD. Economic and practical aspects of thromboprophylaxis with unfractionated and low-molecular-weight heparins in hospitalized medical patients. Clin Appl Thromb Hemost. 2009;15(5) 489-500.
ClinicoEconomics and Outcomes Research

\section{Publish your work in this journal}

ClinicoEconomics \& Outcomes Research is an international, peerreviewed open-access journal focusing on Health Technology Assessment, Pharmacoeconomics and Outcomes Research in the areas of diagnosis, medical devices, and clinical, surgical and pharmacologica intervention. The economic impact of health policy and health systems

\section{Dovepress}

organization also constitute important areas of coverage. The manuscript management system is completely online and includes a very quick and fair peer-review system, which is all easy to use. Visit http://www.dovepress.com/testimonials.php to read real quotes from published authors.

Submit your manuscript here: http://www.dovepress.com/clinicoeconomics-and-outcomes-research-journal 